\title{
Bitcoin fluctuations and the frequency of price overreactions
}

\author{
Guglielmo Maria Caporale ${ }^{1,2} \cdot$ Alex $^{\text {Plastun }}{ }^{3} \cdot$ Viktor Oliinyk $^{3}$
}

Published online: 8 July 2019

(c) The Author(s) 2019

\begin{abstract}
This paper investigates the role of the frequency of price overreactions in the cryptocurrency market in the case of BitCoin over the period 2013-2018. Specifically, it uses a static approach to detect overreactions and then carries out hypothesis testing by means of a variety of statistical methods (both parametric and non-parametric) including ADF tests, Granger causality tests, correlation analysis, regression analysis with dummy variables, ARIMA and ARMAX models, neural net models, and VAR models. Specifically, the hypotheses tested are whether or not the frequency of overreactions (i) is informative about Bitcoin price movements (H1) and (ii) exhibits no seasonality (H2). On the whole, the results suggest that it can provide useful information to predict price dynamics in the cryptocurrency market and for designing trading strategies $(\mathrm{H} 1$ cannot be rejected), whilst there is no evidence of seasonality (H2 cannot be rejected).
\end{abstract}

Keywords Cryptocurrency · Bitcoin · Anomalies · Overreactions · Abnormal returns $\cdot$ Frequency of overreactions

JEL Classification G12 · G17 · C63

\section{Introduction}

Cryptocurrencies have attracted considerable attention since their recent creation and experienced huge swings. For instance, in 2017 Bitcoin prices rose by more than 20 times, but in early 2018 fell by $70 \%$; similar sharp drops had in fact already occurred

$\bowtie$ Guglielmo Maria Caporale

Guglielmo-Maria.Caporale@brunel.ac.uk

Alex Plastun

o.plastun@uabs.sumdu.edu.ua

1 Department of Economics and Finance, Brunel University London, London UB8 3PH, UK

2 CESifo and DIW Berlin, Berlin, Germany

3 Sumy State University, Sumy, Ukraine 
5 times before (June 2011, January 2012, April 2013, November 2013, December 2017). Such significant deviations of asset prices from their average values during certain periods of time are known as overreactions and have been widely analysed in the literature since the seminal paper of De Bondt and Thaler (1985), various studies being carried out for different markets (stocks, FOREX, commodities etc.), countries (developed and emerging), assets (stock prices/indices, currency pairs, oil, gold etc.), and time intervals (daily, weekly, monthly etc.). However, hardly any evidence is available to date on the cryptocurrency market, which is particularly interesting because of its extremely high volatility compared to the FOREX or stock market (see Caporale and Plastun 2018a for details). In the most recent years interest in the cryptocurrency market has increased even further, and price prediction has been investigated in various studies (Ciaian et al. 2016; Balcilar et al. 2017; Khuntia and Pattanayak 2018; Al-Yahyaee et al. 2019 and many others). However, the evidence is still mixed.

The present paper aims to analyse the role of the frequency of overreactions, specifically whether or not it can help predict price behaviour and/or exhibits seasonality, by using daily prices for BitCoin over the period 2013-2018. Overreactions are detected by plotting the distribution of logreturns. Then, the following null hypotheses are tested: (i) the frequency of overreactions is informative about BitCoin price movements (H1), and (ii) it exhibits no seasonality $(\mathrm{H} 2)$. For this purpose a variety of statistical methods (parametric and non-parametric) are used such as ADF tests, Granger causality tests, correlation analysis, regression analysis with dummy variables, ARIMA and ARMAX models, neural net models, and VAR models.

The remainder of the paper is organised as follows. Section 2 contains a brief review of the literature on price overreactions in the cryptocurrency market. Section 3 describes the methodology. Section 4 discusses the empirical results. Section 5 provides some concluding remarks.

\section{Literature review}

According to Hileman and Rauchs (2017) there were more than 300 academic papers devoted to the cryptocurrency market published before the crypto boom; their number has increased further since then. The cryptocurrency market is still relatively young and as a result papers have initially analysed some of its general features (Dwyer 2015a, b; Elbahrawy et al. 2017) or properties such as competitiveness (Halaburda and Gandal 2014). There is only a limited number of studies examining instead its long memory and persistence (Caporale et al. 2018c; Bariviera 2017; Urquhart 2016), efficiency (Urquhart 2016; Bartos 2015), correlations between different cryptocurrencies (Halaburda and Gandal 2014), price predictability (Brown 2014), volatility (Cheung et al. 2015; Carrick 2016).

Bariviera (2017) finds evidence of long memory in the daily dynamics of BitCoin; they also show that persistence in the cryptocurrency market is decreasing. Similar conclusions are reached by Bouri et al. (2016) and Catania and Grassi (2017).

Aggarwal (2019) examines Bitcoin returns and finds strong evidence of market inefficiency (see also Urquhart 2016). Calendar anomalies in the cryptocurrency market are analysed by Kurihara and Fukushima (2017) and Caporale and Plastun (2018c), 
Table 1 Comparative analysis of the average daily price amplitude in different financial markets. Source: Caporale and Plastun (2018a)

\begin{tabular}{lllllll}
\hline Asset & Market & $2014(\%)$ & $2015(\%)$ & $2016(\%)$ & $2017(\%)$ & Average (\%) \\
\hline EURUSD & FOREX & 0.6 & 1.1 & 0.8 & 0.6 & 0.8 \\
Dow-Jones & Stock market & 0.8 & 1.2 & 1.0 & 0.5 & 0.9 \\
$\quad$ Industrial & & & & & & \\
CSI300 & & 1.5 & 3.0 & 1.5 & 0.9 & 1.8 \\
Gold & Commodities & 1.3 & 1.4 & 1.5 & 0.9 & 1.3 \\
Oil & & 1.8 & 3.9 & 3.9 & 2.1 & 2.9 \\
BitCoin & Cryptocurrency & 5.0 & 4.2 & 2.4 & 6.3 & 5.1 \\
LiteCoin & & 6.6 & 6.4 & 2.9 & 9.6 & 7.3 \\
Dash & & 22.0 & 9.0 & 7.1 & 11.3 & 12.1 \\
Ripple & & 7.1 & 4.2 & 3.2 & 12.7 & 7.3 \\
\hline
\end{tabular}

This table presents the average daily price amplitude in different financial markets. The first column specifies the asset being analysed; the second column identifies the type of the financial market; the third, the fourth, the fifth and the sixth columns show the average daily price amplitude estimates for 2014, 2015, 2016 and 2017, respectively; the seventh column shows average daily price amplitude estimates over the period 2014-2017

intraday patterns are explored by Eross et al. (2017), the overreaction hypothesis is tested by Caporale and Plastun (2018a).

Ma and Tanizaki (2019) analyse the day-of-the-week effect for both returns and their volatility in the cryptocurrency market, and find significantly high volatilities on Monday and Thursday. Similar results are reported by Aharon and Qadan (2018). Eross et al. (2019) analyse the intraday dynamics of Bitcoin and find that the trade volume in the cryptocurrency market increases during the day and falls from around 4 pm until midnight.

Caporale and Plastun (2018a) explore overreactions in the cryptocurrency market and find price patterns after overreactions: the next-day price changes in both directions are bigger than after "normal" days. Analysing overreactions in the case of the cryptocurrency market is particularly interesting because of its extreme volatility (see Caporale and Plastun 2018a; Cheung et al. 2015 and Dwyer 2015a, b). Also, its average daily price amplitude is up to 10 times higher than in the FOREX or stock market (see Table 1).

Further, the log return distribution of prices has unusually fat tails (see Table 18), which suggests their being prone to overreactions, which can be helpful to predict future prices and crises. Catania and Grassi (2017) show that price behaviour in the cryptocurrency market is quite complex, with outliers, asymmetries and nonlinearities that are difficult to model.

Al-Yahyaee et al. (2019) try to predict Bitcoin prices using information from a Volatility Uncertainty Index (VIX), whilst Mensi et al. (2019) find evidence of co-movement between Bitcoin and five major cryptocurrencies (Dash, Ethereum, Litecoin, Monero and Ripple). Balcilar et al. (2017) show that information about trade volumes can be used to predict returns in the cryptocurrency market. Aharon and Qadan (2018) show that normally used variables have limited forecasting power for 
Bitcoin prices. Khuntia and Pattanayak (2018) explore time-varying linear and nonlinear dependence in Bitcoin returns. Kristoufek (2014) finds that the trade-exchange ratio plays an essential role in driving Bitcoin price fluctuations in the long run. Ciaian et al. (2016) show that the total number of unique Bitcoin transactions per day is an important determinant of Bitcoin price fluctuations.

Another issue investigated in the literature is whether overreactions exhibit seasonality. De Bondt and Thaler (1985) show that they tend to occur mostly in a specific month of the year, whilst Caporale and Plastun (2018b) do not find evidence of seasonal behaviour in the US stock market. Note also that according to Khuntia and Pattanayak (2018) market efficiency in the cryptocurrency market is evolving over time. Caporale and Plastun (2018a) find evidence in favour of the overreaction hypothesis, whilst Bartos (2015) report that the cryptocurrency market immediately reacts to the arrival of new information and absorbs it; as a result prices are not affected by overreactions.

Whilst most studies examine abnormal returns and the subsequent price behaviour (in general, contrarian movement) for a given time interval (day, week, and month), the current paper focuses on the frequency of abnormal price changes. Only a few papers have considered this issue in the case of the FOREX or stock market (see Govindaraj et al. 2014; Angelovska 2016), and none in the case of the cryptocurrency market. We will aim to show that the frequency of abnormal price changes can be a useful tool for price predictions in the cryptocurrency market.

\section{Methodology}

The first step in the analysis of overreactions is their detection. There are two main methods. One is the dynamic trigger approach, which is based on relative values. Wong (1997) and Caporale and Plastun (2018a) in particular propose to define overreactions on the basis of the number of standard deviations to be added to the average return. The other is the static approach which uses actual price changes as an overreaction criterion. For example, Bremer and Sweeney (1991) use a 10\% price change as a criterion. Caporale and Plastun (2018b) compare these two methods in the case of the US stock market and show that the static approach produces more reliable results. Therefore, this will also be used here.

The static approach was introduced by Sandoval and Franca (2012) and developed by Caporale and Plastun (2018b). Returns are defined as:

$$
S_{t}=\ln \left(P_{t}\right)-\ln \left(P_{t-1}\right)
$$

where $S_{t}$ stands for returns, and $P_{t}$ and $P_{t-1}$ are the close prices of the current and previous day. The next step is analysing the frequency distribution by creating histograms. We plot values $10 \%$ above or below those of the population. Thresholds are then obtained for both positive and negative overreactions, and periods can be identified when returns were above or equal to the threshold.

Such a procedure generates a data set for the frequency of overreactions (at a monthly frequency), which is then divided into 3 subsets including, respectively, the frequency of negative and positive overreactions, and of them all. In this study we 
also use an additional measure (named the "Overreactions multiplier"), namely the negative/positive overreactions ratio:

$$
\text { Overreactions multiplier }_{i}=\frac{\text { frequency of negative overreactions }_{i}}{\text { frequency of positive overreactions } i}
$$

Then, the following hypotheses are tested:

Hypothesis 1 (H1) The frequency of overreactions is informative about price movements in the cryptocurrency market.

There is a body of evidence suggesting that typical price patterns appear in financial markets after abnormal price changes. The relationship between the frequency of overreactions and BitCoin prices is investigated here by running the following regressions (see Eqs. 3 and 4):

$$
Y_{t}=a_{0}+a_{1}^{+} D_{1 t}^{+}+a_{1}^{-} D_{1 t}^{-}+\varepsilon_{t}
$$

where $Y_{t}$ are BitCoin $\log$ differences on day $t ; a_{n}$ are BitCoin mean log differences; $a_{1}^{+}\left(a_{1}^{-}\right)$are coefficients on positive and negative overreactions, respectively; $D_{1 n}^{+}$ $\left(D_{1 n}^{-}\right)$is a dummy variable equal to 1 on positive (negative) overreaction days, and 0 otherwise; $\varepsilon_{t}$ is a random error term at time $t$.

$$
Y_{t}=a_{0}+a_{1} O_{t}^{+}+a_{2} O_{t}^{-}+\varepsilon_{t}
$$

where $Y_{t}$ are BitCoin log differences on day $t ; a_{0}$ are BitCoin mean log differences; $a_{1}$ $\left(a_{2}\right)$ are coefficients on positive and negative overreactions, respectively; $O_{t}^{+}\left(O_{t}^{-}\right)$is the number of positive (negative) overreaction days during a period $t ; \varepsilon_{t}$ is a random error term at time $t$.

The size, sign and statistical significance of the coefficients provide information about the possible influence of the frequency of overreactions on BitCoin log returns.

To assess the performance of the regression models a multilayer perceptron (MLP) method will be used (Rumelhart and McClelland 1986). This method is based on neural networks modelling. The algorithm is as follows. The data is divided into 3 groups: the learning group (50\%), the test group (25\%), and the control group (25\%). The learning process in the neural network consists of 2 stages: the first stage is based on an inverse distribution method (number of periods -100 , training speed -0.01 ) and the second uses a conjugate gradient method (number of periods -500 ). This procedure generates an optimal neural net. The results from the neural net are then compared with those from the regression analysis.

To obtain further evidence an $\operatorname{ARIMA}(\mathrm{p}, \mathrm{d}, \mathrm{q})$ model is also estimated:

$$
Y_{t}=a_{0}+\sum_{i=1}^{p} \psi_{t-i} Y_{t-i}+\sum_{j=1}^{q} \theta_{t-j} \varepsilon_{t-j}+\varepsilon_{t}
$$

where $Y_{t}$ are BitCoin log differences on day $t ; a_{0}$ is a constant; $\psi_{t-i} ; \theta_{t-j}$ are coefficients of the $\log$ differences on day $t-i$ and a random error term at time $t-j$, 
respectively; $Y_{t-\mathrm{i}}$ are BitCoin log differences on day $t-i ; \varepsilon_{t-j}$ is a random error term at time $t-j ; \varepsilon_{t}$ is a random error term at time $t$.

To improve the basic $\operatorname{ARIMA}(\mathrm{p}, \mathrm{d}, \mathrm{q})$ specification additional variables are then added, namely the frequency of negative and positive overreactions, respectively:

$$
Y_{t}=a_{0}+\sum_{i=1}^{p} \psi_{t-i} Y_{t-i}+\sum_{i=1}^{q} \theta_{t-i} \varepsilon_{t-i}+\sum_{i=1}^{s_{1}} a_{t-i} O F_{t-i}^{-}+\sum_{i=1}^{s_{2}} b_{t-i} O F_{t-i}^{+}+\varepsilon_{t}
$$

Information criteria, specifically AIC (Akaike 1974) and BIC (Schwarz 1978), are used to select the best ARMAX specification for BitCoin log returns.

As a robustness check, VAR models are also estimated:

$$
y_{t}=a_{0}+\sum_{i=1}^{p} A_{i} y_{t-i}+\varepsilon_{t}
$$

where $y_{t}=\left(y_{t}^{1}, y_{t}^{2}, \ldots, y_{t}^{k}\right)$ is a time series vector; $A_{\mathrm{t}}$ is a time-invariant matrix; $a_{0}$ is a vector of constants; $\varepsilon_{t}$ is a vector of error terms. Impulse response functions (IRFs) are then computed and Variance Decomposition (VD) is also carried out. In addition, Granger causality tests (Granger 1969) and Augmented Dickey-Fuller tests (Dickey and Fuller, 1979) are performed.

Hypothesis $2(\mathrm{H} 2)$ The frequency of overreactions exhibits no seasonality.

We perform a variety of statistical tests, both parametric (ANOVA analysis) and non-parametric (Kruskal-Wallis tests), for seasonality in the monthly frequency of overreactions, which provides information on whether or not overreactions are more likely in some specific months of the year.

\section{Empirical results}

The data used are BitCoin daily and monthly prices for the period 01.05.201331.05.2018; the data source is CoinMarket (https://coinmarketcap.com/). As a first step, the frequency distribution of log returns is analysed (see Table 18 and Fig. 6). As can be seen, two symmetric fat tails are present in the distribution. The next step is the choice of thresholds for detecting overreactions. To obtain a sufficient number of observations we consider values $\pm 10 \%$ of the average from the population, namely -0.04 for negative overreactions and 0.05 for positive ones. Detailed results are presented in Appendix 2.

Visual inspection of Figs. 7 and 8 suggests that the frequency of overreactions varies over time (see Table 19). To provide additional evidence we carry out ANOVA analysis and Kruskal-Wallis tests (Table 2); both confirm that the differences between years are statistically significant, i.e. that the frequency of overreactions is time-varying.

Next we carry out a correlation analysis. Table 3 reports the results for different parameters, namely the number of negative (Over_negative) and positive overreactions (Over_positive), as well as the total number of overreactions (All_over) and the 
Table 2 Results of ANOVA and non-parametric Kruskal-Wallis tests for statistical differences in the frequency of overreactions between different years

\begin{tabular}{llll}
\hline$F$ & $p$-value & $F$ critical & Null hypothesis \\
\hline ANOVA test & 0.000 & 2.81 & Rejected \\
7.24 & $p$-value & Critical value & Null hypothesis \\
\hline Adjusted $H$ & & & \\
\hline Kruskal-Wallis test & 0.001 & 9.49 & Rejected \\
\hline 14.98 & &
\end{tabular}

This table presents the results from the ANOVA and Kruskal-Wallis tests for statistical differences in the frequency of overreactions between different years. The first column reports the $F$ value from the ANOVA analysis and the Adjusted $H$ for the Kruskal-Wallis test; the second column shows $p$-values; the third column shows critical values; the fourth column specifies whether or not the Null hypothesis is rejected

Table 3 Correlation analysis between the frequency of overreactions and different BitCoin series indicators

\begin{tabular}{llcc}
\hline Parameter & BitCoin close prices & BitCoin returns & BitCoin logreturns \\
\hline Over_negative & 0.50 & -0.21 & -0.34 \\
Over_positive & 0.41 & 0.62 & 0.53 \\
All_over & 0.53 & 0.25 & 0.13 \\
Over_mult & 0.15 & -0.40 & -0.60 \\
\hline
\end{tabular}

This table presents coefficient estimates from the correlation analysis. The first column specifies the parameter being considered: the number of negative overreactions ("Over_negative"), the number of positive overreactions ("Over_positive"), as well as the total number of overreactions ("All_over") and the overreactions multiplier ("Over_mult"); the second column shows the parameter estimates for BitCoin close prices; the third column reports the parameter estimates for BitCoin returns; the fourth column shows the parameter estimates for BitCoin log returns

overreactions multiplier (Over_mult) and indicators (BitCoin close prices, BitCoin returns, BitCoin logreturns).

There appears to be a positive (rather than negative, as one would expect) correlation between BitCoin prices and negative overreactions. By contrast, there is a negative correlation in the case of returns and log returns. The overreaction multiplier exhibits a rather strong negative correlation with BitCoin log returns. Finally, the overall number of overreactions has a rather weak correlation with prices.

To make sure that there is no need to shift the data in any direction we carry out a cross-correlation analysis of these indicators at the time intervals $t$ and $t+i$, where $I \in\{-10, \ldots, 10\}$. Figure 1 reports the cross-correlation between Bitcoin log returns and the frequency of (both positive and negative) overreactions for the whole sample period for different leads and lags. The highest coefficient corresponds to lag length zero, which means that there is no need to shift the data.

To analyse further the relationship between BitCoin log returns and the frequency of overreactions we carry out ADF tests on the series of interest (see Table 4).

The unit root null is rejected in most cases implying stationarity. The next step is testing $\mathrm{H} 1$ by running a simple linear regression and one with dummy variables (see Sect. 3 for details). The results for BitCoin closes, returns and log returns regressed 


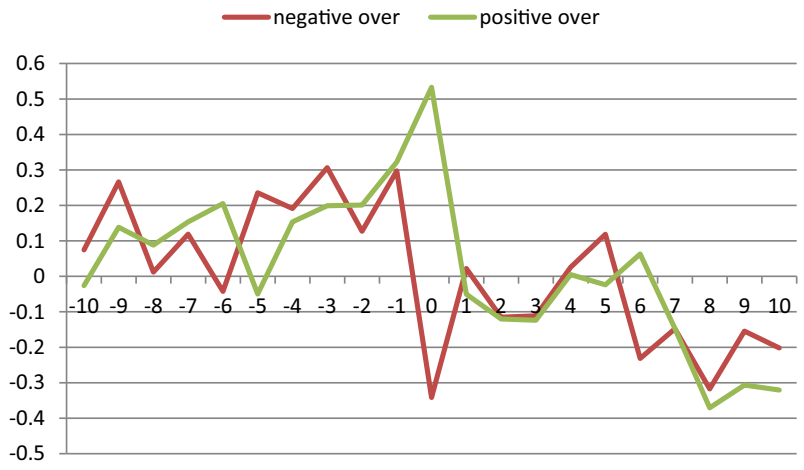

Fig. 1 Cross-correlation between Bitcoin log returns and frequency of overreactions over the whole sample period for different leads and lags. This figure displays the correlation coefficients between BitCoin log returns and the frequency of negative overreactions ("negative over") as well as the frequency of positive overreactions ("positive over") over the whole sample period with lags in the interval $[-10, \ldots .+10]$

Table 4 Augmented Dickey-Fuller test: BitCoin log returns and overreactions frequency data

\begin{tabular}{lcccc}
\hline Parameter & Logreturns & Over_all & Over_negative & Over_positive \\
\hline Augmented Dickey-Fuller test (intercept) & & & & \\
Augmented Dickey-Fuller test statistic & -7.55 & -2.87 & -5.48 & -3.39 \\
Probability & 0.0000 & 0.0549 & 0.0000 & 0.0152 \\
Test critical values (5\% level) & -2.89 & -2.89 & -2.89 & -2.89 \\
Null hypothesis & Rejected & Not rejected & Rejected & Rejected \\
Augmented Dickey-Fuller test (trend and intercept) & & & \\
Augmented Dickey-Fuller test statistic & -7.47 & -2.91 & -5.59 & -3.37 \\
Probability & 0.0000 & 0.1677 & 0.0001 & 0.0650 \\
Test critical values (5\% level) & -3.41 & -3.41 & -3.41 & -3.41 \\
Null hypothesis & Rejected & Not rejected & Rejected & Not rejected \\
Augmented Dickey-Fuller test (intercept, & 1-st difference) & & \\
Augmented Dickey-Fuller test statistic & -6.86 & -12.21 & -13.95 & -11.65 \\
Probability & 0.0000 & 0.0001 & 0.0000 & 0.0000 \\
Test critical values (5\% level) & -3.41 & -3.41 & -3.41 & -3.41 \\
Null hypothesis & Rejected & Rejected & Rejected & Rejected \\
\hline
\end{tabular}

This table presents the results of the Augmented Dickey-Fuller test. The first column specifies the parameter of the Augmented Dickey-Fuller test being considered, the second column shows the results for BitCoin $\log$ returns ("logreturns"); the third column for all overreactions ("Over_all"); the fourth column shows parameter estimates for negative overreactions ("Over_negative") and the fifth column for positive overreactions ("Over_positive"). The Lag Length was chosen on the basis of the Schwarz information criterion. The results are significant at the $5 \%$ level

against all overreactions, negative and positive overreactions are presented in Tables 5, 6 , and 7, respectively. In all three cases the specification with the highest explanatory power is the one including negative and positive overreactions as separate variables, though in the case of BitCoin closes the positive sign of the coefficient on negative overreactions is not what one would expect. 
Table 5 Regression analysis results: BitCoin closes

\begin{tabular}{|c|c|c|c|}
\hline Parameter & All overreactions & $\begin{array}{l}\text { Negative and positive } \\
\text { overreactions as separate } \\
\text { variables }\end{array}$ & $\begin{array}{l}\text { Regression with dummy } \\
\text { variables }\end{array}$ \\
\hline$a_{0}$ & $\begin{array}{l}-100.64 \\
(0.85)\end{array}$ & $\begin{array}{l}-158.22 \\
(0.77)\end{array}$ & $\begin{array}{l}368.88 \mathrm{x} \\
(0.32)\end{array}$ \\
\hline $\begin{array}{l}\text { Slope for the } \\
\text { overreactions (all } \\
\text { overreactions) }\end{array}$ & $\begin{array}{l}350.77 \\
(0.00)\end{array}$ & - & - \\
\hline $\begin{array}{l}\text { Slope for the } \\
\text { overreactions (negative } \\
\text { overreactions) }\end{array}$ & - & $\begin{array}{l}475.44 \\
(0.00)\end{array}$ & $\begin{array}{l}551.28 \\
(0.00)\end{array}$ \\
\hline $\begin{array}{l}\text { Slope for the } \\
\text { overreactions (positive } \\
\text { overreactions) }\end{array}$ & - & $\begin{array}{l}237.43 \\
(0.10)\end{array}$ & $\begin{array}{l}514.33 \\
(0.00)\end{array}$ \\
\hline$F$-test & $\begin{array}{l}22.55 \\
(0.00)\end{array}$ & $\begin{array}{l}11.69 \\
(0.00)\end{array}$ & $\begin{array}{l}16.32 \\
(0.00)\end{array}$ \\
\hline Multiple $R$ & 0.53 & 0.54 & 0.46 \\
\hline
\end{tabular}

This table presents the coefficient estimates and $p$-values (in parentheses) from the regression models of BitCoin closes. The first column defines the parameter, the second reports coefficient estimates for all overreactions, the third for negative and positive overreactions as separate variables, the fourth for a regression analysis with dummy variables

Table 6 Regression analysis results: BitCoin returns

\begin{tabular}{|c|c|c|c|}
\hline Parameter & All overreactions & $\begin{array}{l}\text { Negative and positive } \\
\text { overreactions as separate } \\
\text { variables }\end{array}$ & $\begin{array}{l}\text { Regression with dummy } \\
\text { variables }\end{array}$ \\
\hline$a_{0}$ & $\begin{array}{l}-0.0442 \\
(0.72)\end{array}$ & $\begin{array}{l}0.0395 \\
(0.55)\end{array}$ & $\begin{array}{l}0.0119 \\
(0.88)\end{array}$ \\
\hline $\begin{array}{l}\text { Slope for the } \\
\text { overreactions (all } \\
\text { overreactions) }\end{array}$ & $\begin{array}{l}0.0328 \\
(0.00)\end{array}$ & - & - \\
\hline $\begin{array}{l}\text { Slope for the } \\
\text { overreactions (negative } \\
\text { overreactions) }\end{array}$ & - & $\begin{array}{l}-0.1597 \\
(0.00)\end{array}$ & $\begin{array}{l}0.0023 \\
(0.00)\end{array}$ \\
\hline $\begin{array}{l}\text { Slope for the } \\
\text { overreactions (positive } \\
\text { overreactions) }\end{array}$ & - & $\begin{array}{l}0.2076 \\
(0.00)\end{array}$ & $\begin{array}{l}0.0922 \\
(0.00)\end{array}$ \\
\hline$F$-test & $\begin{array}{l}3.93 \\
(0.05)\end{array}$ & $\begin{array}{l}77.64 \\
(0.00)\end{array}$ & $\begin{array}{l}8.71 \\
(0.00)\end{array}$ \\
\hline Multiple $R$ & 0.25 & 0.86 & 0.36 \\
\hline
\end{tabular}

This table presents coefficient estimates and $p$-values (in parentheses) from the regression models of BitCoin returns. The first column defines the parameter, the second reports coefficient estimates for all overreactions, the third for negative and positive overreactions as separate variables, the fourth for a regression analysis with dummy variables

To sum up, consistently with the theoretical priors, the total number of overreactions is not a significant regressor in any case. The best specification is the simple linear 
Table 7 Regression analysis results: BitCoin log returns

\begin{tabular}{llll}
\hline Parameter & All overreactions & $\begin{array}{l}\text { Negative and positive } \\
\text { overreactions as } \\
\text { separate variables }\end{array}$ & $\begin{array}{l}\text { Regression with } \\
\text { dummy variables }\end{array}$ \\
\hline$a_{0}$ & -0.0200 & 0.0645 & 0.0368 \\
& $(0.72)$ & $(0.04)$ & $(0.35)$ \\
Slope for the overreactions & 0.0084 & - & - \\
$\quad$ all overreactions) & $(0.33)$ & -0.0939 & -0.0122 \\
$\begin{array}{c}\text { Slope for the overreactions } \\
\text { (negative overreactions) }\end{array}$ & - & $(0.00)$ & $(0.32)$ \\
Slope for the overreactions & - & 0.1013 & 0.0355 \\
(positive overreactions) & & $(0.00)$ & $(0.00)$ \\
F-test & 0.98 & 96.48 & 6.85 \\
& $(0.33)$ & $(0.00)$ & $(0.00)$ \\
Multiple $R$ & 0.13 & 0.88 & 0.32
\end{tabular}

This table presents coefficient estimates and $p$-values (in parentheses) from the regression models of BitCoin $\log$ returns. The first column defines the parameter, the second reports coefficient estimates for all overreactions, the third for negative and positive overreactions as separate variables, the fourth for the case of a regression analysis with dummy variables

multiplier regression model with the frequency of positive and negative overreactions as regressors, and the best results are obtained in the case of log returns as indicated by the multiple $\mathrm{R}$ for the whole model and the $p$-values for the estimated coefficients. Specifically, the selected specification is the following:

$$
\text { Bitcoin log } \text { return }_{i}=0.0645-0.0939 \times O F_{i}^{-}+0.1013 \times O F_{i}^{+}
$$

which implies a strong positive (negative) relationship between Bitcoin log returns and the frequency of positive (negative) overreactions. On the whole, the above evidence supports H1. The difference between the actual and estimated values of Bitcoin can be seen as an indication of whether Bitcoin is over- or under-estimated and therefore a price increase or decrease should be expected. Obviously, BitCoin should be bought in the case of undervaluation and sold in the case of overvaluation till the divergence between actual and estimated values disappears, at which stage positions should be closed.

As mentioned before, to show that the selected specification is indeed the best linear model we use the multilayer perceptron (MLP) method. Negative and positive overreactions are the independent variables (the entry points) and log returns are the dependent variable (the exit point) in the neural net. The learning algorithm previously described generates the following optimal neural net MLP 2-2-3-1:1 (Fig. 2).

We compare it with the linear neural net L 2-2-1:1 model, which consists of 2 inputs and 1 output. The results are presented in Tables 8 and 9 .

As can be seen, the neural net based on the multilayer perceptron structure provides better results than the linear neural net: the control error is lower (0.0392 (MLP) vs $0.0801(\mathrm{~L}))$; the standard deviation error and the data ratio are also lower $(0.4673 \mathrm{vs}$ $0.5078)$; the correlation is higher $(0.8844$ vs 0.8719$)$. 


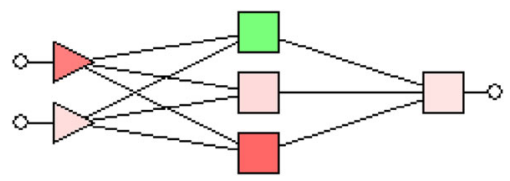

Fig. 2 Optimal neural net structure. This figure displays the optimal neural network structure: the entry points (red and pink triangles), neural network methods (learning, control, test; the green, pink and red squares, respectively), and the exit point (BitCoin log returns; the pink square on the right)

Table 8 Comparative characteristics of neural networks

\begin{tabular}{lllllllll}
\hline Architecture & \multicolumn{2}{l}{ Performance } & & & \multicolumn{2}{l}{ Errors } & & \\
\cline { 2 - 3 } & Learning & Control & Test & & Learning & Control & Test \\
\hline MLP 2-2-3-1:1 & 0.4484 & 0.4547 & 0.5657 & & 0.0811 & 0.0392 & 0.0630 \\
L 2-2-1:1 & 0.3809 & 0.6265 & 0.8314 & & 0.0664 & & 0.0801 & 0.0836 \\
\hline
\end{tabular}

This table presents comparative characteristics of the neural networks from the multilayer perceptron (MLP) method. The first column reports the architecture of the network models, the second, third and fourth columns show the estimates for the performance parameters of the models learning, control and test, respectively; the fifth, sixth and seventh columns show the estimates for errors of the models learning, control and test, respectively

Table 9 Quality comparison of neural networks

\begin{tabular}{llr}
\hline Parameters & \multicolumn{2}{l}{ Type of neural net } \\
\cline { 2 - 3 } & MLP 2-2-3-1:1 & L 2-2-1:1 \\
\hline Average & 0.0677 & 0.0677 \\
Standard deviation & 0.3103 & 0.3103 \\
Mean error & 0.0067 & -0.0158 \\
Standard deviation error & 0.1450 & 0.1576 \\
Mean absolute error & 0.1106 & 0.1244 \\
Standard deviation error and data ratio & 0.4673 & 0.5078 \\
Correlation & 0.8844 & 0.8719 \\
\hline
\end{tabular}

This table presents the neural network estimates from the multilayer perceptron (MLP) method. The first column defines the parameters for the network models, the second column shows the parameter estimates for the MLP 2-2-3-1:1 model; the third column provides parameter estimates for the L 2-2-1:1 model

Figure 3 shows the distribution of BitCoin log returns, actual vs estimated (from the regression model and the neural network).

As can be seen the estimates (from the regression model and the neural network, respectively) are very similar and very close to the actual values, which suggests that the regression model (Eq. 8) captures very well the behaviour of BitCoin prices.

We also estimate ARIMA(p, d, q) models with $p \leq 3 ; q \leq 3 ; d=0$ choosing the best specification on the basis of the AIC and BIC information criteria. Specifically, we select the following models: $\operatorname{ARIMA}(2,0,2)$ (on the basis of the AIC criterion); $\operatorname{ARIMA}(1,0,0)$ and $\operatorname{ARIMA}(0,0,1)$ (on the basis of the BIC criterion). The parameter estimates are presented in Table 10. 


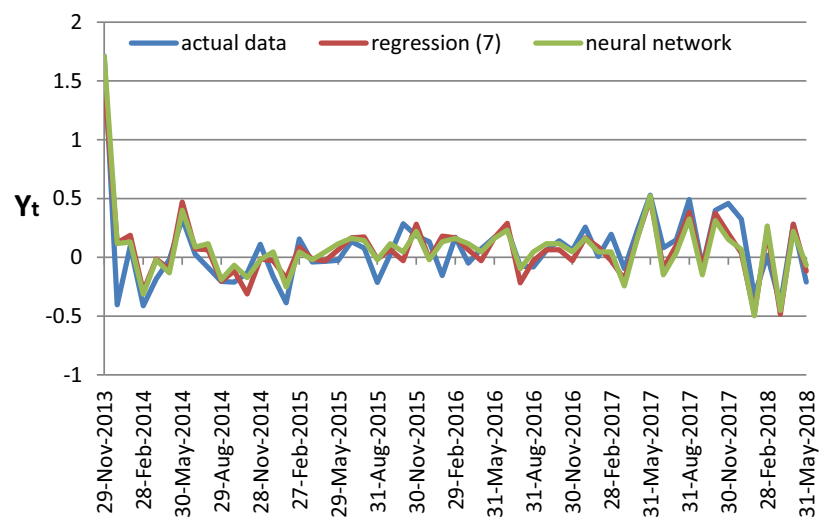

Fig. 3 Distribution of BitCoin log returns: actual vs estimated (from the regression model and the neural network). This figure presents estimates and comparison between actual BitCoin log returns ("actual data") and estimates based both on the regression model ("regression (7)") and the neural network model ("neural network") over the sample period considered

Table 10 Parameter estimates for the best ARIMA models

\begin{tabular}{llll}
\hline Parameter & Model 1: $\operatorname{ARIMA}(2,0,2)$ & Model 2: $\operatorname{ARIMA}(1,0,0)$ & $\operatorname{Model~3:~} \operatorname{ARIMA}(0,0,1)$ \\
\hline$a_{0}$ & 0.0717 & $0.0676^{*}$ & $0.0676^{*}$ \\
& $(0.1019)$ & $(0.0931)$ & $(0.0929)$ \\
$\psi_{t-1}$ & 0.2622 & 0.0048 & - \\
& $(0.1568)$ & $(0.9702)$ & - \\
$\psi_{t-2}$ & $-0.6935^{* * *}$ & - & - \\
& $(0.0000)$ & & 0.0044 \\
$\theta_{t-1}$ & $-0.2938^{* * *}$ & - & - \\
$\theta_{t-2}$ & $(0.0052)$ & - & $-9714)$ \\
& $1.0000^{* * *}$ & - & 35.8788 \\
AIC & $(0.0000)$ & 35.8773 & 42.1618 \\
BIC & 35.7555 & 42.1617 & \\
\hline
\end{tabular}

This table presents the coefficient estimates and $p$-values (in parentheses) from the ARIMA models. The first column reports the parameter estimates for BitCoin $\log$ returns $(Y)$, the second column shows the parameter estimates for Model 1: ARIMA (2, 0, 2); the third column for Model 2: ARIMA (1, 0, 0); the fourth column for Model 3: ARIMA $(0,0,1)$. Significance at the $1 \%, 5 \%$, and $10 \%$ levels is indicated by $* * *$ and $*$, respectively

As can be seen, Model 1 captures best the behaviour of BitCoin log returns: all regressors are significant at the $1 \%$ level, except $\psi_{t-i}$, and AIC has the smallest value.

To establish whether this specification can be improved by including information about the frequency of overreactions, ARMAX models (see Eq. 6) are estimated adding as regressors $O F_{t}^{-}$(negative overreactions) and $O F_{t}^{+}$(positive overreactions). The estimated parameters are reported in Table 11. Model 4 adds the frequency of negative overreactions and positive overreactions to Model 1. Model 5 is a version of Model 4 chosen on the basis of the AIC and BIC criteria. 
Table 11 Estimated parameters for the ARMAX models
This table presents coefficient estimates and $p$-values (in parentheses) from the ARMAX models. The first column reports parameter estimates for BitCoin $\log$ returns $(Y)$, the second column shows parameter estimates for model 4 and the third column for model 5 . Significance at the 1, 5, and $10 \%$ levels is indicated by $* * *$ and **, respectively

\begin{tabular}{|c|c|c|}
\hline Parameter & Model 4 & Model 5 \\
\hline$a_{0}$ & $\begin{array}{l}0.0669 \\
(0.3870)\end{array}$ & $\begin{array}{l}0.0821 \\
(0.3027)\end{array}$ \\
\hline$\psi_{t-1}$ & $\begin{array}{l}-0.1316 \\
(0.3155)\end{array}$ & $\begin{array}{l}0.7101^{* * *} \\
(0.0003)\end{array}$ \\
\hline$\psi_{t-2}$ & $\begin{array}{l}0.8245^{* * *} \\
(0.0000)\end{array}$ & $\begin{array}{l}0.8895^{* * *} \\
(0.0000)\end{array}$ \\
\hline$\psi_{t-3}$ & - & $\begin{array}{l}-0.7811^{* * * *} \\
(0.0000)\end{array}$ \\
\hline$\theta_{t-1}$ & $\begin{array}{l}-0.3383 \\
(0.1969)\end{array}$ & $\begin{array}{l}-1.1925^{* * *} \\
(0.0000)\end{array}$ \\
\hline$\theta_{t-2}$ & $\begin{array}{l}-0.1307 \\
(0.4683)\end{array}$ & - \\
\hline$\theta_{t-3}$ & - & $\begin{array}{l}0.5468^{* * *} \\
(0.0000)\end{array}$ \\
\hline$a_{t-1}$ & $\begin{array}{l}-0.0590^{* * *} \\
(0.0008)\end{array}$ & $\begin{array}{l}-0.0513^{* * *} \\
(0.0026)\end{array}$ \\
\hline$a_{t-2}$ & $\begin{array}{l}0.0663^{* * *} \\
(0.0000)\end{array}$ & $\begin{array}{l}0.0585^{* * *} \\
(0.0000)\end{array}$ \\
\hline$a_{t-3}$ & $\begin{array}{l}-0.0493^{* * *} \\
(0.0006)\end{array}$ & $\begin{array}{l}-0.0476^{* * *} \\
(0.0005)\end{array}$ \\
\hline$a_{t-4}$ & $\begin{array}{l}0.0333^{* *} \\
(0.0107)\end{array}$ & $\begin{array}{l}0.0345^{* * *} \\
(0.0068)\end{array}$ \\
\hline$b_{t-1}$ & $\begin{array}{l}0.0467^{* * *} \\
(0.0025)\end{array}$ & $\begin{array}{l}0.0410^{* *} \\
(0.0212)\end{array}$ \\
\hline$b_{t-2}$ & $\begin{array}{l}-0.0498^{* * *} \\
(0.0000)\end{array}$ & $\begin{array}{l}-0.0506^{* * *} \\
(0.0002)\end{array}$ \\
\hline$b_{t-6}$ & $\begin{array}{l}0.0103 \\
(0.3459)\end{array}$ & $\begin{array}{l}0.0069 \\
(0.4879)\end{array}$ \\
\hline AIC & 22.2441 & 19.3993 \\
\hline BIC & 48.3395 & 47.5019 \\
\hline
\end{tabular}

Clearly, Model 5 is the best specification for modelling BitCoin log returns: all parameters are statistically significant (except $b_{t-6}$ ), and there is no evidence of misspecification from the residual diagnostic tests. Figure 4 plots the estimated and actual values of BitCoin log returns.

Table 12 reports Granger causality tests between BitCoin log returns and both negative $\left(O F^{-}\right)$and positive overreactions $\left(O F^{+}\right)$. As can be seen, the null hypothesis of no causality is rejected for negative $\left(O F^{-}\right)$and positive overreactions $\left(O F^{+}\right)$, but not for BitCoin log returns $(Y)$, and therefore there is evidence that forecasts of the latter can be improved by including in a VAR specification the two former variables. The optimal lag length implied by both the AIC and BIC criteria is one (see Table 13). The estimates for the VAR(1)-model are reported in Table 14.

This model appears to be data congruent: it is stable (no root lies outside the unit circle), and there is no evidence of autocorrelation in the residuals. The IRF analysis (see Appendix 3, Figs. 9, 10 and 11 for details) shows that, in response to a 1-standard 


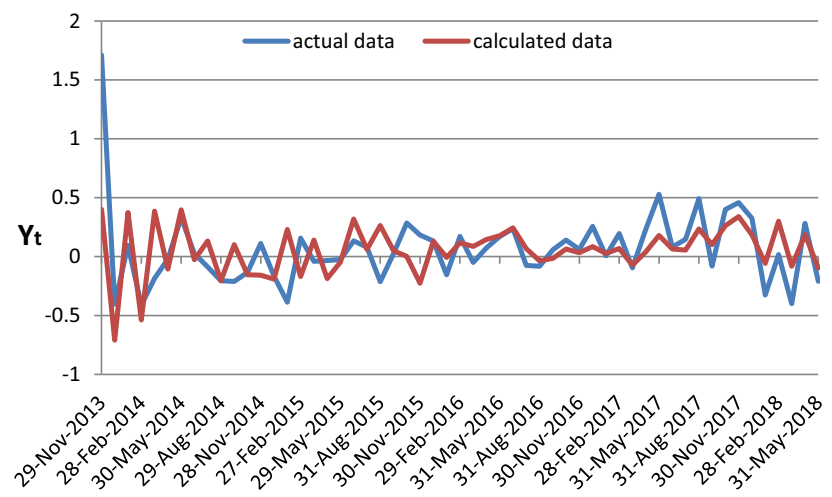

Fig. 4 Distribution of BitCoin log returns: actual vs estimated (based on Model 5). This figure presents comparison between actual BitCoin log returns ("actual data") and estimates based on model 5 ("calculated data") over the sample period considered

Table 12 Granger Causality Tests between BitCoin log returns and both negative $\left(\mathrm{OF}^{-}\right)$and positive overreactions $(O F+)$

\begin{tabular}{|c|c|c|c|c|c|c|}
\hline \multirow{3}{*}{ Excluded } & \multicolumn{6}{|c|}{ Null hypothesis: no causality } \\
\hline & \multicolumn{2}{|l|}{$Y$} & \multicolumn{2}{|l|}{$O F^{-}$} & \multicolumn{2}{|l|}{$O F^{+}$} \\
\hline & Chi-sq & Probability & Chi-sq & Probability & Chi-sq & Probability \\
\hline$Y$ & - & - & 3.6428 & $0.0563^{*}$ & 8.6296 & $0.0033^{* * *}$ \\
\hline$O F^{-}$ & 1.2724 & 0.2593 & - & - & 7.8424 & $0.0051^{* * *}$ \\
\hline$O F^{+}$ & 1.4541 & 0.2279 & $0.0011^{* * *}$ & 0.9725 & - & - \\
\hline All & 1.4902 & 0.4747 & 14.4342 & $0.0007^{* * *}$ & 9.0730 & $0.0107^{* *}$ \\
\hline Null hypothesis & \multicolumn{2}{|c|}{ Not rejected } & \multicolumn{2}{|l|}{ Rejected } & \multicolumn{2}{|l|}{ Rejected } \\
\hline
\end{tabular}

This table presents chi-square and probability estimates from the Granger Causality Tests. The first column reports the parameters used in Granger Causality Tests, the second and third columns show, respectively, chisquare and probability estimates for BitCoin log returns $(Y)$; the fourth and fifth columns show, respectively, chi-square and probability estimates for negative overreactions $\left(O F^{-}\right)$; the sixth and seventh columns show, respectively, chi-square and probability estimates for positive overreactions $\left(\mathrm{OF}^{+}\right)$. Significance at the $1 \%$, $5 \%$, and $10 \%$ levels is indicated by $* * *, * *$, and $*$, respectively

deviation shock to log returns, both negative $\left(O F^{-}\right)$and positive overreactions $\left(O F^{+}\right)$ revert to their equilibrium value within six periods, whereas it takes log returns only one period to revert to equilibrium. There is hardly any response of $\log$ returns to shocks to either positive or negative overreactions, whilst both the latter variables tend to settle down after about six periods. The variance decomposition (VD) results are presented in Table 15. They suggest the following:

- The behaviour of $Y$ is mostly explained by its previous dynamics (97.4\%); $O F^{-}$ accounts for only $0.2 \%$ of its variance, and $O F^{+}$for only $2.4 \%$.

- The behaviour of $O F^{-}$is also mainly determined by its previous dynamics (76.7\%), with $Y$ explaining only $22.7 \%$ of its variance and $O F^{+}$only $0.6 \%$. 
Table 13 VAR lag length selection criteria

\begin{tabular}{llr}
\hline Lags & AIC & BIC \\
\hline 1 & 7.4380 & 7.8969 \\
2 & 7.5663 & 8.3694 \\
3 & 7.7687 & 8.9160 \\
4 & 8.0171 & 9.5085 \\
5 & 7.9496 & 9.7852 \\
6 & 8.0571 & 10.2368 \\
7 & 8.2555 & 10.7793 \\
8 & 8.0228 & 10.8908 \\
9 & 7.6051 & 10.8173 \\
10 & 7.6916 & 11.2480 \\
\hline
\end{tabular}

Table 14 VAR(1) parameter estimates

\begin{tabular}{llll}
\hline Parameter & $Y$ & $O F^{-}$ & $O F^{+}$ \\
\hline Const & 0.0568 & $1.2280^{* *}$ & $1.0447^{*}$ \\
$Y(-1)$ & $(0.3984)$ & $(0.0157)$ & $(0.0553)$ \\
& 0.3004 & $3.8884^{*}$ & $6.4797^{* * *}$ \\
$O F^{-}(-1)$ & $(0.2818)$ & $(0.0615)$ & $(0.0048)$ \\
& 0.0354 & $0.4658^{* *}$ & $0.7012^{* * *}$ \\
$O F^{+}(-1)$ & $(0.2642)$ & $(0.0489)$ & $(0.0070)$ \\
& -0.0391 & 0.0082 & -0.2904 \\
$R$-squared & $(0.2330)$ & $(0.9726)$ & $(0.2666)$ \\
Adj. $R$-squared & 0.0264 & 0.2874 & 0.2831 \\
$F$-statistic & -0.0267 & 0.2485 & 0.2440 \\
$p$-value & 0.4971 & 7.3953 & 7.2412 \\
Akaike AIC & 0.6857 & $0.0003^{* * *}$ & $0.0004^{* * *}$ \\
BIC criterion & 0.6009 & 4.5958 & 4.7547 \\
Durbin-Watson stat & 0.7418 & 4.7366 & 4.8956 \\
Akaike AIC & 2.0280 & 2.2936 & 2.2109 \\
BIC criterion & 8.3870 & & \\
\hline
\end{tabular}

This table presents coefficient estimates and $p$-values (in parentheses) from estimating a VAR(1) model. The first column defines the parameters. The second column reports parameter estimates for BitCoin log returns $(\mathrm{Y})$, the third column shows parameter estimates for negative overreactions $\left(O F^{-}\right)$and the fourth column for positive overreactions $\left(\mathrm{OF}^{+}\right)$. Significance at the $1 \%, 5 \%$, and $10 \%$ levels is indicated by ***, **, and *, respectively

- The behaviour of $O F^{+}$is mostly accounted for by the $O F^{-}$dynamics (43\%), with $Y$ explaining $36.9 \%$ of its variance and $O F^{+} 20.1 \%$.

Finally, we address the issue of seasonality (H2). Figure 5 suggests that the overreactions frequency tends to be higher at the end and the start of the year and lower at other times. Also, there appears to be a mid-year cycle: the frequency starts to increase 
Table 15 Variance Decomposition

\begin{tabular}{|c|c|c|c|c|}
\hline \multirow[t]{2}{*}{ Variable } & \multirow[t]{2}{*}{ Lag } & \multicolumn{3}{|c|}{$\begin{array}{l}\text { Percentage of the variance accounted } \\
\text { for by a variable }\end{array}$} \\
\hline & & $Y$ & $O F^{-}$ & $O F^{+}$ \\
\hline \multirow[t]{3}{*}{$Y$} & 1 & 100.00 & 0.00 & 0.00 \\
\hline & 2 & 97.42 & 0.19 & 2.39 \\
\hline & $3>$ & 97.42 & 0.19 & 2.39 \\
\hline \multirow[t]{3}{*}{$O F^{-}$} & 1 & 17.04 & 82.96 & 0.00 \\
\hline & 2 & 22.02 & 77.98 & 0.00 \\
\hline & $3>$ & 22.65 & 76.74 & 0.61 \\
\hline \multirow[t]{3}{*}{$O F^{+}$} & 1 & 36.13 & 38.65 & 25.22 \\
\hline & 2 & 37.58 & 41.79 & 20.63 \\
\hline & $3>$ & 36.86 & 43.04 & 20.10 \\
\hline
\end{tabular}

This table reports the percentage of the variance accounted for each variable according to the variance decomposition. The first column specifies the variables: BitCoin log returns $(Y)$, negative overreactions $\left(O F^{-}\right)$and positive overreactions $\left(O F^{+}\right)$; the second column shows lags; the third, fourth and fifth columns report the parameter estimates for BitCoin log returns $(Y)$, negative overreactions $\left(O F^{-}\right)$and positive overreactions $\left(\mathrm{OF}^{+}\right)$, respectively

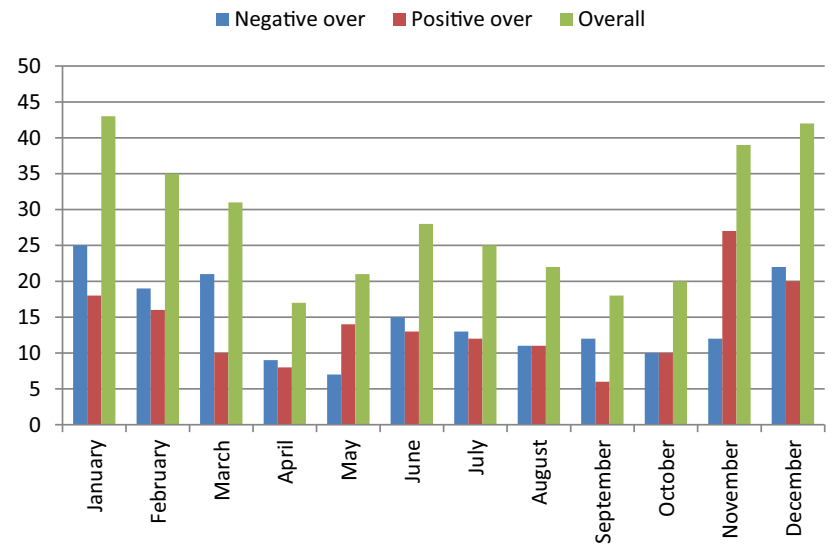

Fig. 5 Monthly seasonality in the overreaction frequency. This figure presents the frequency of price overreactions by month over the whole sample period. "Negative over" represents the frequency of negative overreactions; "Positive over" represents the frequency of positive overreactions; "Overall" represents the overall frequency of overreactions

in April, peaks in June-July and then falls till September with a "W" seasonality pattern.

Formal parametric (ANOVA) and non-parametric (Kruskal-Wallis) tests are performed; the results are presented in Tables 16 and 17. As can be seen, there are no statistically significant differences between the frequency of overreactions in different months of the year (i.e. no evidence of seasonality), i.e. $\mathrm{H} 2$ cannot be rejected, which is consistent with the visual evidence based on Fig. 3. 
Table 16 Parametric ANOVA of monthly seasonality in the overreaction frequency

\begin{tabular}{llll}
\hline Parameter & $\begin{array}{l}\text { Frequency of negative } \\
\text { overreactions }\end{array}$ & $\begin{array}{l}\text { Frequency of positive } \\
\text { overreactions }\end{array}$ & $\begin{array}{l}\text { Frequency of } \\
\text { overreactions (overall) }\end{array}$ \\
\hline$F$ & 0.90 & 0.77 & 0.72 \\
$p$-value & 0.5461 & 0.6596 & 0.7055 \\
$F$ critical & 1.99 & 1.99 & 1.99 \\
Null hypothesis & Not rejected & Not rejected & Not rejected \\
\hline
\end{tabular}

This table presents the estimates from an ANOVA analysis of monthly seasonality in the overreaction frequency. The first column reports the main parameters of the ANOVA analysis, the second column shows the parameter estimates for negative overreactions; the third column reports the parameter estimates for positive overreactions; the forth column provides parameter estimates for overall overreactions. The null hypothesis is tested at the $5 \%$ significance level

Table 17 Non-parametric Kruskal-Wallis of monthly seasonality in the overreaction frequency

\begin{tabular}{llll}
\hline Parameter & $\begin{array}{l}\text { Frequency of negative } \\
\text { overreactions }\end{array}$ & $\begin{array}{l}\text { Frequency of positive } \\
\text { overreactions }\end{array}$ & $\begin{array}{l}\text { Frequency of } \\
\text { overreactions (overall) }\end{array}$ \\
\hline Adjusted $H$ & 7.21 & 7.16 & 8.32 \\
d.f. & 11 & 11 & 11 \\
$p$-value & 0.78 & 0.79 & 0.68 \\
Critical value & 19.675 & 19.675 & 19.675 \\
Null hypothesis & Not rejected & Not rejected & Not rejected \\
\hline
\end{tabular}

This table presents the results from the Kruskal-Wallis tests of monthly seasonality in the overreaction frequency. The first column reports the main parameters of the Kruskal-Wallis test, the second column shows the parameter estimates for negative overreactions; the third column provides the parameter estimates for positive overreactions; the forth column reports the parameter estimates for overall overreactions. The null hypothesis is tested at the $5 \%$ significance level

\section{Conclusion}

This paper investigates the role of the frequency of price overreactions in the cryptocurrency market in the case of BitCoin over the period 2013-2018. Specifically, it uses a static approach to detect overreactions and then carries out hypothesis testing by means of a variety of statistical methods (both parametric and non-parametric) including ADF tests, Granger causality tests, correlation analysis, regression analysis with dummy variables, ARIMA and ARMAX models, neural net models, and VAR models. Specifically, the hypotheses tested are whether or not the frequency of overreactions (i) is informative about Bitcoin price movements (H1) and (ii) exhibits no seasonality $(\mathrm{H} 2)$.

On the whole, the results suggest that the frequency of price overreactions can provide useful information to predict price dynamics in the cryptocurrency market and for designing trading strategies (H1 cannot be rejected) in the specific case of BitCoin. However, these findings are somewhat mixed: stronger evidence of a predictive role for the frequency of price overreactions is found when estimating neural net and ARMAX models as opposed to VAR models. As for the possible presence of seasonality, the evidence is very clear: no seasonal patterns are detected for the frequency of price overreactions (H2 cannot be rejected). 
Acknowledgements Alex Plastun gratefully acknowledges financial support from the Ministry of Education and Science of Ukraine (0117U003936). The authors are grateful to the editor and an anonymous referee for their useful comments and suggestions.

Open Access This article is distributed under the terms of the Creative Commons Attribution 4.0 International License (http://creativecommons.org/licenses/by/4.0/), which permits unrestricted use, distribution, and reproduction in any medium, provided you give appropriate credit to the original author(s) and the source, provide a link to the Creative Commons license, and indicate if changes were made.

\section{Appendix}

\section{Frequency distribution of BitCoin}

Table 18 Frequency distribution of BitCoin, 2013-2018

\begin{tabular}{lc}
\hline BitCoin Return & Frequency \\
\hline$<-0.04$ & 181 \\
-0.03 & 75 \\
-0.02 & 96 \\
-0.01 & 164 \\
0 & 331 \\
0.01 & 345 \\
0.02 & 207 \\
0.03 & 136 \\
0.04 & 88 \\
0.05 & 68 \\
$>0.05$ & 168 \\
\hline
\end{tabular}

This table presents estimates of the frequency distribution for BitCoin returns over the period 01.05.2013-31.05.2018. The first column reports the values for BitCoin returns, the second column the corresponding frequency

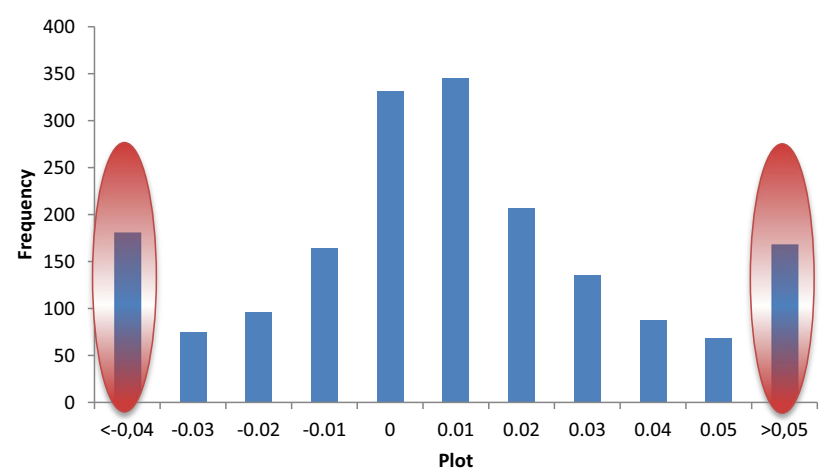

Fig. 6 Frequency distribution of BitCoin, 2013-2018. This figure presents the frequency distribution estimates for BitCoin returns over the period 01.05.2013-31.05.2018. The plot size is displayed on the $x$ axis; the number of returns fitting the corresponding plot is displayed on the $y$ axis 


\section{Frequency of overreactions}

Table 19 Frequency of overreactions over the period 2013-2018, annual

\begin{tabular}{lllll}
\hline Year & Negative over & Positive over & All over & Mult \\
\hline 2013 & 29 & 41 & 70 & 0.7 \\
2014 & 35 & 22 & 57 & 1.6 \\
2015 & 25 & 21 & 46 & 1.2 \\
2016 & 11 & 11 & 22 & 1.0 \\
2017 & 50 & 53 & 103 & 0.9 \\
2018 & 30 & 19 & 49 & 1.6 \\
Mean & 30 & 30 & 60 & 1.1 \\
SD & 12.7 & 15.2 & 26.8 & 0.32 \\
\hline
\end{tabular}

This table presents the frequency of overreactions estimates for BitCoin returns over the period 01.05.2013-31.05.2018. The first column reports the years and descriptive statistics; the second column shows estimates for negative overreactions ("Negative over"); the third column reports estimates for positive overreactions ("Positive over"); the fourth column provides estimates for all overreactions ("All over"); the fifth column reports estimates for the overreaction multiplier ("Mult")

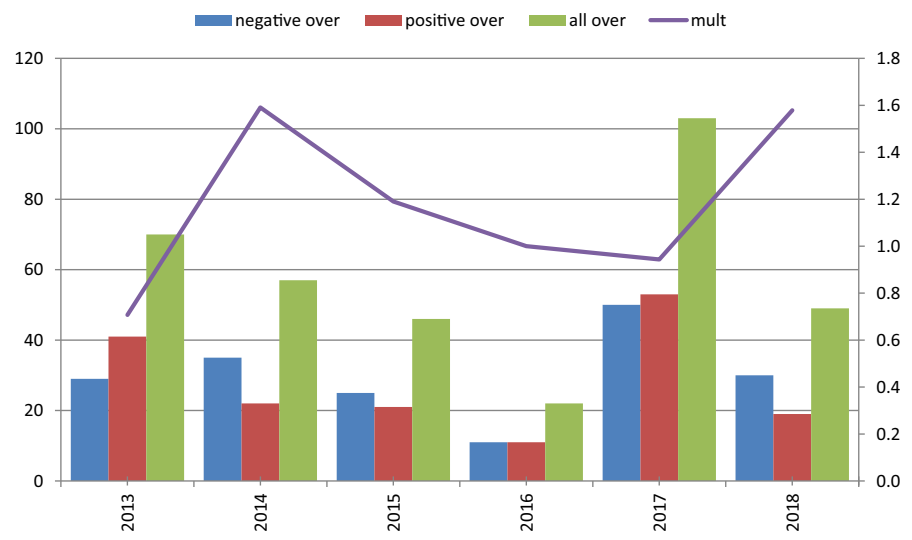

Fig. 7 Frequency of overreactions: dynamic analysis over the period 2013-2018, annual data. This figure presents frequency of overreactions estimates for BitCoin returns over the period 01.05.2013-31.05.2018. "Negative over" stands for the estimates for negative overreactions; "Positive over", "All over" and "Mult" stand, respectively, for the estimates for positive overreactions, all overreactions and the overreaction multiplier. The frequency of the overreactions parameter is displayed on the $y$ axis; the year is displayed on the $x$ axis 


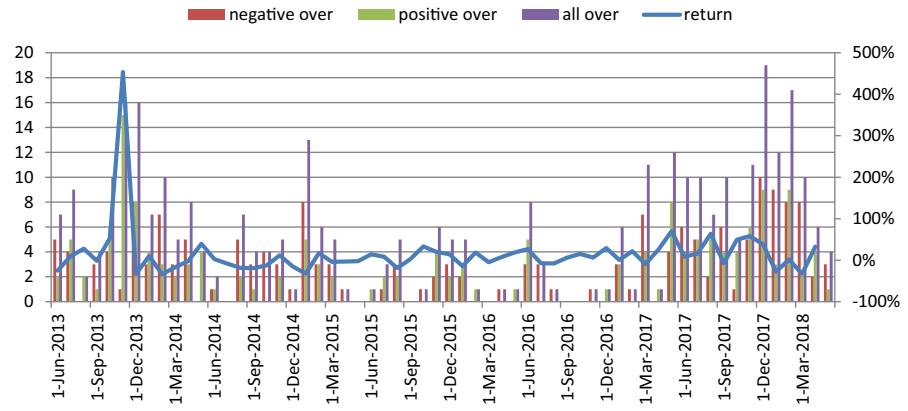

Fig. 8 Frequency of overreactions: dynamic analysis over the period 2013-2018, monthly data. This figure presents the frequency of overreactions estimates for BitCoin returns over the period 01.05.2013-31.05.2018 for the case of monthly data. "Negative over" stands for the estimates for negative overreactions; "Positive over", "All over" and "Mult" stand for the positive overreactions, all overreactions and the overreaction multiplier, respectively. The frequency of the overreactions parameter is displayed on the $y$ axis; the year is displayed on the $x$ axis

\section{Impulse response function (IRF) analysis: log returns ( ()$-D$; negative overreactions $\left(O F^{-}\right)-E$; positive overreactions $\left(O F^{+}\right)-F$}

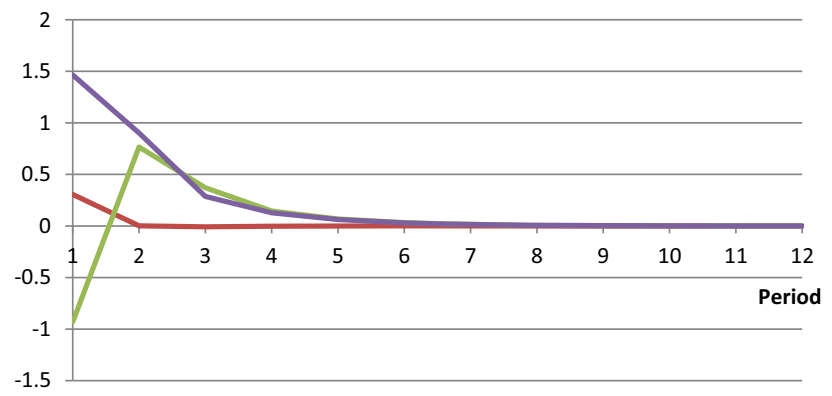

log returns $\longrightarrow$ negative overreactions positive overreactions

Fig. 9 Response to a 1-standard deviation shock to log returns. This figure presents estimates from the Impulse Response Function (IRF) analysis for BitCoin log returns $(Y)$, negative overreactions and positive overreactions based on a 1-standard deviation shock to log returns. The estimates of the Impulse Response Function are displayed on the $y$ axis; the time interval is displayed on the $x$ axis 


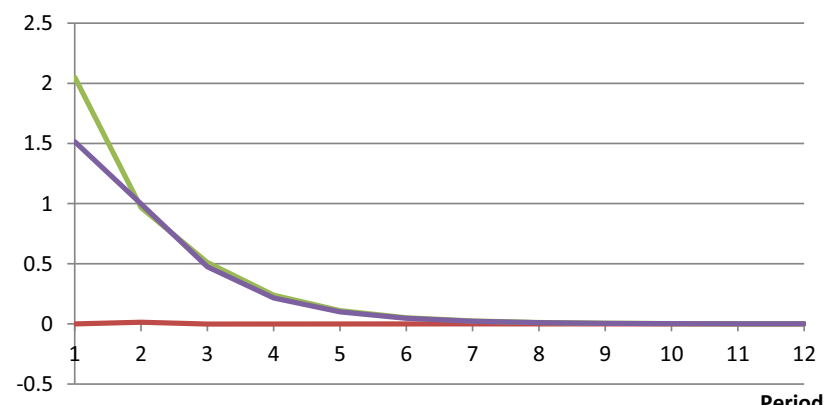

Log returns $\longrightarrow$ negative overreactions $\longrightarrow$ positive overreactions

Fig. 10 Response to a 1-standard deviation shock to negative overreactions. This figure presents estimates from the Impulse Response Function (IRF) analysis for BitCoin log returns $(Y)$, negative overreactions and positive overreactions based on a 1-standard deviation shock to negative overreactions. The estimates of the Impulse Response Function are displayed on the $y$ axis; the time interval is displayed on the $x$ axis

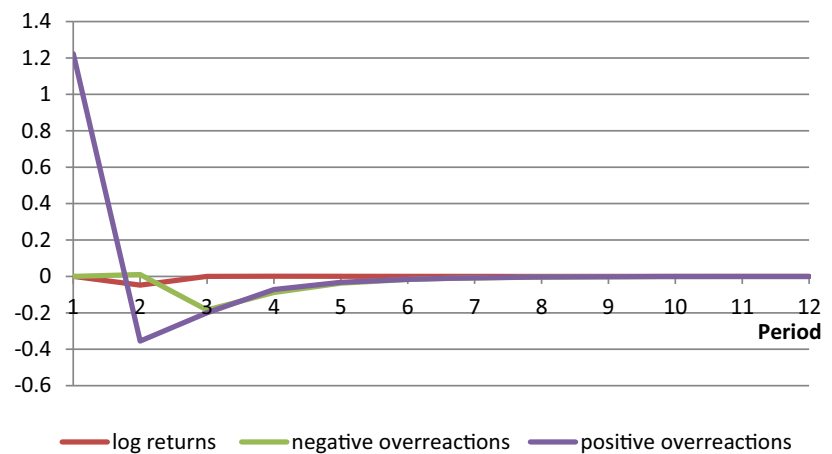

Fig. 11 Response to a 1-standard deviation shock to positive overreactions. This figure presents estimates from the Impulse Response Function (IRF) analysis for BitCoin log returns $(Y)$, negative overreactions and positive overreactions based on a 1-standard deviation shock to positive overreactions. The estimates of the Impulse Response Function are displayed on the $y$ axis; the time interval is displayed on the $x$ axis

\section{References}

Aggarwal, D.: Do bitcoins follow a random walk model? Res. Econ. 73(1), 15-22 (2019)

Aharon, D., Qadan, M.: Bitcoin and the day-of-the-week effect. Finance Res. Lett. (2018). https://doi.org/ 10.1016/j.frl.2018.12.004

Akaike, H.: A new look at the statistical model identification. IEEE Trans. Autom. Control 19(6), 716-723 (1974)

Al-Yahyaee, K., Rehman, M., Mensi, W., Al-Jarrah, I.: Can uncertainty indices predict Bitcoin prices? A revisited analysis using partial and multivariate wavelet approaches. N. Am. J. Econ. Finance 49, 47-56 (2019)

Angelovska, J.: Large share price movements, reasons and market reaction. Management 21, 1-17 (2016) Balcilar, M., Bouri, E., Gupta, R., Rouband, D.: Can volume predict bitcoin returns and volatility? A qunatiles based approach. Econ. Model. 64, 74-81 (2017)

Bariviera, A.F.: The inefficiency of bitcoin revisited: a dynamic approach. Econ. Lett. 161, 1-4 (2017)

Bartos, J.: Does Bitcoin follow the hypothesis of efficient market? Int. J. Econ. Sci. IV(2), 10-23 (2015) 
Bouri, E., Gil-Alana, L.A., Gupta, R., Roubaud, D.: Modelling Long Memory Volatility in the Bitcoin Market: Evidence of Persistence and Structural Breaks. University of Pretoria, working paper 201654. (2016). https://ideas.repec.org/p/pre/wpaper/201654.html

Bremer, M., Sweeney, R.J.: The reversal of large stock price decreases. J. Finance 46, 747-754 (1991)

Brown, W.L.: An Analysis of Bitcoin Market Efficiency Through Measures of Short-Horizon Return Predictability and Market Liquidity. CMC Senior Theses. Paper 864. http://scholarship.claremont.edu/ cmc_theses/864 (2014)

Caporale, G.M., Gil-Alana, A., Plastun, A.: Persistence in the cryptocurrency market. Res. Int. Bus. Finance 46, 141-148 (2018)

Caporale, G.M., Plastun, A.: Price Overreactions in the Cryptocurrency Market. DIW Berlin Discussion Paper No. 1718. http://dx.doi.org/10.2139/ssrn.3113177 (2018a)

Caporale, G.M., Plastun, A.: On the Frequency of Price Overreactions. CESifo Working Paper Series No. 7011. SSRN: https://ssrn.com/abstract= $(2018 \mathrm{~b})$

Caporale, G.M., Plastun, A.: The day of the week effect in the cryptocurrency market Finance Research Letters Available online 19 November 2018, ISSN 1544-6123 https://doi.org/10.1016/j.frl.2018.11. 012 (2018c)

Carrick, J.: Bitcoin as a complement to emerging market currencies. Emerg. Mark. Finance Trade 52(2016), 2321-2334 (2016)

Catania, L., Grassi, S.: Modelling Crypto-Currencies Financial Time-Series. http://dx.doi.org/10.2139/ssrn. 3028486 (2017)

Cheung, A., Roca, E., Su, J.-J.: Crypto-currency bubbles: an application of the Phillips-Shi-Yu (2013) methodology on Mt. Gox Bitcoin Prices. Appl. Econ. 47, 2348-2358 (2015)

Ciaian, P., Rajcaniova, M., Kancs, D.A.: The economics of BitCoin price formation. Appl. Econ. 48(19), 1799-1815 (2016)

De Bondt, W., Thaler, R.: Does the stock market overreact? J. Finance 40, 793-808 (1985)

Dickey, D.A., Fuller, W.A.: Distribution for the estimates for autoregressive time series with a unit root. J. Am. Stat. Assoc. 74, 427-431 (1979)

Dwyer, G.P.: The economics of Bitcoin and similar private digital currencies. J. Financ. Stab. 17, 81-91 (2015a)

Dwyer, G.P.: The economics of Bitcoin and similar private digital currencies. J. Financ. Stab. 17, 81-91 (2015b)

Elbahrawy, A., Alessandretti, L., Kandler, A., Pastor-Satorras, R., Baronchelli, A.: Evolutionary dynamics of the cryptocurrency market. R. Soc. Open Sci. (2017). https://doi.org/10.1098/rsos.170623

Eross, A., McGroarty, F., Urquhart, A., Wolfe, S.: The intraday dynamics of bitcoin. Res. Int. Bus. Finance 49, 71-81 (2019)

Eross, A., Mcgroarty, F., Urquhart, A., Wolfe, S.: The Intraday Dynamics of Bitcoin. https://www. researchgate.net/publication/318966774

Govindaraj, S., Livnat, J., Savor, P., Zhaoe, Ch.: Large price changes and subsequent returns. J. Invest. Manag. 12(3), 31-58 (2014)

Granger, C.W.J.: Investigating causal relations by econometric models and cross-spectral methods. Econometrica 37, 424-438 (1969)

Halaburda, H., Gandal, N.: Competition in the Cryptocurrency Market. NET Institute Working Paper No. 14-17. SSRN: https://ssrn.com/abstract=2506463 or http://dx.doi.org/10.2139/ssrn.2506463 (2014)

Hileman, D., Rauchs, M.: Global Cryptocurrency Benchmarking Study. Cambridge Center for Alternative Finance, London (2017)

Khuntia, S., Pattanayak, J.: Adaptive market hypothesis and evolving predictability of bitcoin. Econ. Lett. 167, 26-28 (2018)

Kristoufek, L.: What are the main drivers of the Bitcoin price? Evidence from wavelet coherence analysis. PLoS ONE 10(4), e0123923 (2014). https://doi.org/10.1371/journal.pone.0123923

Kurihara, Y., Fukushima, A.: The market efficiency of Bitcoin: a weekly anomaly perspective. J. Appl. Finance Bank. 7(3), 57-64 (2017)

Ma, D., Tanizaki, H.: The day-of-the-week effect on Bitcoin return and volatility. Res. Int. Bus. Finance 49, 127-136 (2019)

Mensi, W., Rehman, M., Al-Yahyaee, K., Al-Jarrah, I., Kang, S.: Time frequency analysis of the commonalities between Bitcoin and major Cryptocurrencies: portfolio risk management implications. N. Am. J. Econ. Finance 48, 283-294 (2019) 
Rumelhart, D.E., McClelland, J.L.: Parallel Distributed Processing: Explorations in the Microstructures of Cognition. MIT Press, Cambridge (1986)

Junior, L.S., Franca, I.D.P.: Correlation of financial markets in times of crisis. Phys. A Stat. Mech. Appl. 391(1-2), 187-208 (2012)

Schwarz, G.E.: Estimating the dimension of a model. Ann. Stat. 6(2), 461-464 (1978)

Urquhart, A.: The inefficiency of Bitcoin. Econ. Lett. 148, 80-82 (2016)

Wong, M.: Abnormal stock returns following large one-day advances and declines: evidence from AsianPacific markets. Financ. Eng. Jpn. Mark. 4, 71-177 (1997)

Publisher's Note Springer Nature remains neutral with regard to jurisdictional claims in published maps and institutional affiliations

Guglielmo Maria Caporale (MSc, PhD, LSE) is Professor of Economics and Finance and Director of the Centre for Empirical Finance at Brunel University, London. He is also a Visiting Professor at London South Bank University, a Research Professor at DIW Berlin, a CESifo Research Network Fellow, and an Associate Researcher at the International Laboratory of Financial Economics (LFE), International College of Economics and Finance (ICEF), Higher School of Economics (HSE), Moscow. Prior to taking up his current position, he was a Research Officer at the National Institute of Economic and Social Research in London; a Research Fellow and then a Senior Research Fellow at the Centre for Economic Forecasting at the London Business School; Professor of Economics at the University of East London; Professor of Economics and Finance as well as Director of the Centre for Monetary and Financial Economics at London South Bank University.

Alex Plastun is Professor at the Chair of International Economic Relations in the Sumy State University. Before joining Sumy State University, he was a trader and analyst in several investment companies. He still trades in the different financial markets using his own trading strategies. Professor Plastun tries to use his experience as a trader to inform academic theory and is particularly interested in market inefficiencies. $\mathrm{He}$ has published in such outlets as the Journal of Economics and Finance, Computational Economics, and Corporate Ownership and Control. Professor Plastun was awarded a PhD in Finance by the Ukrainian Academy of Banking.

Oliynyk Victor is Professor at the Chair of Economic Cybernetics in the Sumy State University. His research interests include actuarial calculations, insurance, optimisation and management of financial flows. Professor Oliynyk has published more than 60 scientific and more than 20 pedagogical papers in the areas of finance, economics and mathematics. Professor Oliynyk was awarded a PhD in Physics and Mathematics in 1993. 